\title{
Infant feeding and subsequent risk of atopic eczema
}

\author{
W J MOORE, R E MIDWINTER, A F MORRIS, J R T COLLEY, AND J F SOOTHILL \\ Department of Epidemiology and Community Medicine, University of Bristol, and Institute of Child \\ Health, London
}

SUMMARY An attempted controlled trial of exclusively breast fed neonates with atopic parents, to assess the effectiveness of breast feeding in preventing atopic allergy, was not successfully achieved. Analysis of the data as an observational study, however, provided evidence that breast feeding offers some protection against eczema in genetically vulnerable infants. Feeds of soya preparations were associated with eczema as often as cows' milk based feeds.

Nearly 50 years ago Grulee and Sanford reported that eczema was increasingly common, and they suggested that this was due to the introduction of artificial infant feeding. ${ }^{1}$ Eczema is becoming more common $^{2}$ and is associated with the state of atopy for which inherited predispostion plays an important part: if one parent has a history of atopy then the risk to the child is doubled and if both have a history the risk is doubled again. ${ }^{3}$ Concordance for monozygotic twins is fourfold greater than for dizygotic twins, ${ }^{4}$ but environmental influences are also implicated. Many reports have studied populations selected for high genetic risk, including the only randomised controlled trial of the association of infant feeding with subsequent development of allergic disease, which found that infants of atopic parents fed soya feeds developed less eczema and respiratory allergy than those fed cows' milk feeds. ${ }^{5}$ In 1977 a prospective observational study reported that eczema was less prevalent in infants at risk if they were exclusively breast fed than if they were fed wholly or partially artificial feed. ${ }^{6}$ Some observational studies have confirmed this, ${ }^{78}$ but others, some retrospective or of unselected populations, have reported conflicting findings. ${ }^{9-12}$

We attempted to carry out a randomised controlled trial of breast feeding in a large number of infants with atopic parents. Mothers were randomised either to receive the usual advice on infant feeding or to be recommended to breast feed exclusively, but if a substitute feed was unavoidable to use a preparation of soya rather than a preparation of cows' milk.

\section{Subjects and methods}

We tested the hypothesis that infants with a parental history of asthma or eczema are less likely to develop atopic eczema during the first year of life if they are breast fed for the first 3 months and not exposed to cows' milk or solids during this period.

We studied a population of infants born between June 1979 and December 1980 at the Bristol Maternity Hospital to parents with a history of eczema or asthma, or both. To confirm the findings of an earlier study of atopic eczema during the first year of life only about 60 babies needed to be studied. ${ }^{6}$ The sample size that we used, however, was estimated on the basis of a possible associated reduction in the incidence of asthma in later childhood. If the incidence of asthma was to be halved by a regimen of avoiding cows' milk about 500 infants would need to be studied. A pilot study at the Bristol Maternity Hospital in 1978 had predicted that 500 infants with an atopic parental family history could be recruited in one year, but there was a decrease in the birth rate and an 18 month recruitment period was necessary. The pilot study had also shown that about half of the infants had received some cows' milk before discharge from hospital.

Women attending the hospital for antenatal care are questioned routinely if they or their partners have a history of eczema or asthma. Between June 1979 and December 1980 all those with such a history were seen between 34 and 38 weeks' gestation by a member of the research team. In a standardised interview history was rechecked, the trial was explained, and the women were asked if they would agree to take part. Those who agreed were allocated randomly to an experimental or control group. Women in the experimental group were asked to breast feed their babies for at least the first three months; avoid giving their babies solids 
during this time; and if extra feed was necessary to use a soya based feed (Cow and Gate) instead of a preparation of cows' milk. Those in the control group were given standard advice on feeding in use at the hospital; the cows' milk feed in use was SMA Gold Cap. Women whose dates of delivery were in doubt, those with multiple pregnancies, and those who were not white were excluded from the trial.

The research team consisted of two health visitors and a medical officer with considerable experience in child health. They were responsible for recruitment and the day to day running of the trial. The birth of a normal full term infant to a member of the trial was shortly followed by a visit from one of the team; the mother and baby were then visited daily until discharge from hospital. At these visits mothers in the experimental group were given intensive encouragement and advice on feeding. Those in the control group received routine advice on feeding from ward staff. All mothers were seen on the day of discharge and were given feeding diaries, which they were asked to complete daily for the first 3 months of the baby's life.

Before the trial began cooperation was sought from local general practitioners, community physicians, health visitors, and midwives. Community nursing staff were informed when a mother and baby in the trial were discharged from hospital and were asked to contact the research team should any problems in feeding arise. In addition, mothers in the experimental group were given the telephone number of a 24 hour advisory service that was available. A team member, in cooperation with the local health visitor, visited babies in the experimental group at home when they were 4-6 weeks old. No contact was made with babies in the control group at this time.

Each infant in the trial was seen subsequently at the age of 3,6, and 12 months, either at home or at the hospital. At 3 months a detailed history of feeding was taken by one of the health visitors and was checked against the diary. The medical officer, working without the knowledge of the history of feeding, took a full medical history and carried out a clinical examination. Skin lesions were classified by distribution and type. Eczematous skin lesions were classified into one of four grades ${ }^{6}: 0=$ normal skin; $1=$ dry skin, cradle cap, and mild perioral erythema; $2=$ some or all of these features with, in addition, an area of skin, usually on the face or behind the ears, that was red, scaly, cracked, or weeping; and $3=$ as 2 but more extensive lesions usually on the face, trunk, and limbs. Grades 2 and 3 were regarded as eczema, but grades 0 and 1 were not. At 6 and 12 months the medical officer again took a medical history and carried out a full clinical examination. During these examinations blood samples were taken and a skin prick test performed.

\section{Results}

In 35 of the 625 mothers identified as eligible to enter the study a history of asthma or eczema, or both, was not substantiated; a further 32 mothers were not available for interview; 28 were not recruited for various reasons, including being in another study, having a fetal abnormality, or having already delivered the infant; and five refused to enter the study. The 525 mothers thus recruited were allocated randomly either to the experimental $(n=250)$ or control group $(n=275)$, from which 23 and 27 , respectively were lost during the 12 months' follow up for the reasons shown in Table 1. The analyses are based on 475 infants who were followed up until the age of 1 year.

During the first 3 months of life only a quarter of the infants were exclusively breast fed: the proportion was similar in the experimental and control groups (Table 2). The prevalence of eczema at the age of 3 months was similar in both groups. Failure to comply with allocated feeding made analysis of the data as a controlled trial impossible.

The data can, however, be analysed as an observational study of the cumulative prevalence of eczema during the first year of life according to

Table 1 Infants lost to follow up during first year of life by cause and number

\begin{tabular}{lccc}
\hline & $\begin{array}{l}\text { Experimental } \\
\text { group } \\
(n=250)\end{array}$ & $\begin{array}{l}\text { Control } \\
\text { group } \\
(n=275)\end{array}$ & $\begin{array}{l}\text { Total } \\
(n=525)\end{array}$ \\
\hline Neonatal death & 1 & 1 & 2 \\
$\begin{array}{l}\text { Death 28 days - 1 year } \\
\text { Gestation <37 weeks }\end{array}$ & 0 & 2 & 2 \\
$\begin{array}{l}\text { Illness in baby or mother, } \\
\text { or both }\end{array}$ & 4 & 3 & 5 \\
Lost to follow up & 5 & 2 & 6 \\
Withdrew from study & 11 & 7 & 12 \\
Total losses & 23 & 12 & 23 \\
Followed up for 1 year & 227 & 27 & 50 \\
\hline
\end{tabular}

Table 2 Feeding regimen during first 12 weeks of life

\begin{tabular}{lccc}
\hline Feeding regimen & $\begin{array}{l}\text { Experimental } \\
\text { group (\%) }\end{array}$ & $\begin{array}{l}\text { Control } \\
\text { group (\%) }\end{array}$ & Total (\%) \\
\hline $\begin{array}{l}\text { Breast fed only } \\
\text { Soya preparation only or } \\
\text { soya preparation and } \\
\text { breast fed only }\end{array}$ & $58(26)$ & $65(26)$ & $123(26)$ \\
$\begin{array}{l}\text { Any cows milk or solids, } \\
\text { or both }\end{array}$ & $110^{*}(48)$ & $182(73)$ & $292(62)$ \\
\begin{tabular}{l} 
Total \\
\hline
\end{tabular} & $227(100)$ & $248(99)$ & $475(101)$ \\
\hline
\end{tabular}

${ }^{*}$ Includes one infant with absent data on whether solids given. 
actual feeding regimen. The prevalence of eczema at 3 months was related to the early introduction of cows' milk (Table 3). Infants who had not been given cows' milk - that is, were exclusively breast fed, were breast fed and given soya preparations, or given soya preparations only-during the first 4 weeks of life had a prevalence of eczema of $13 \%$ (41 out of 313 ) compared with $23 \%$ (37 of 162) for those who had received any cows' milk by the fourth week of life. The cumulative figure for eczema at 3 months for babies who had not been given any cows' milk during the first 8 weeks was $14 \%$ (37 of 274) compared with $20 \%$ (41 of 201) for those given cows' milk. Fourteen per cent (34 of 248) of infants who had not been given cows' milk for the first 12 weeks and $19 \%$ (44 of 227 ) of those who had, had eczema at 3 months.

The mode of feeding during the first 4 weeks of life had a maximum effect on the difference in the prevalence of eczema at 3 months (Table 3), therefore, the feeding regimen during this time was compared with the prevalence of eczema. At 3 and 6 months the cumulative prevalence of eczema in infants receiving any cows' milk during the first 4 weeks was significantly greater than in those who did not receive cows' milk, but this was not so at 1 year (Table 4). Of the 89 babies who received some soya based feed during the first 4 weeks, $13(15 \%)$ had eczema at 3 months compared with $13 \%$ of infants exclusively breast fed and $23 \%$ who had received some cows' milk. The difference, however, in the prevalence of eczema between infants who were given soya preparations and those given preparations of cows' milk was not significant.

Thirty six babies in the experimental group had

Table 3 Time first cows' milk given related to eczema at 3 months

\begin{tabular}{ll}
\hline First cows' milk & Proportion with eczema at 3 months (\%) \\
\hline Weeks $1-4$ & $37 / 162(23)$ \\
Weeks $5-8$ & $4 / 39(10)$ \\
Weeks $9-12$ & $3 / 26(12)$ \\
$>12$ weeks & $34 / 248(14)$ \\
\hline
\end{tabular}

Table 4 Eczema during first year of life related to feeding regimen during first 4 weeks

\begin{tabular}{lccc}
\hline Eczema & \multicolumn{4}{l}{ Cows' milk given in weeks $1-4(\%)$} \\
\cline { 2 - 4 } & Yes & No & $\chi^{2}(l d f)$ \\
\hline At 3 months & $37(23)$ & $41(13)$ & $6.69 \quad \mathrm{P}<0.01$ \\
At 6 months. & $55(34)$ & $78(25)$ & $3.88 \quad \mathrm{P}<0.05$ \\
At 12 months & $65(40)$ & $116(37)$ & $0.30 \mathrm{NS}$ \\
Total & 162 & 313 & \\
\hline
\end{tabular}

Table 5 Eczema at 3 months related to feeding regimen during first 4 weeks

\begin{tabular}{ll}
\hline Feeding regimen & $\begin{array}{l}\text { Proportion with eczema } \\
\text { at } 3 \text { months }(\%)\end{array}$ \\
\hline Breast fed only & $28 / 224(13)$ \\
Breast fed and soya preparation & $11 / 79(14)$ \\
Breast fed and cows' milk & $30 / 127(24)$ \\
Soya preparation only & $2 / 10(20)$ \\
Cows' milk only & $7 / 35(20)$ \\
Total & $78 / 475(16)$ \\
\hline
\end{tabular}

received only one or two soya feeds but were otherwise exclusively breast fed during the first 4 weeks, four $(11 \%)$ had eczema at 3 months. Similarly 25 babies in the control group had received only one or two cows' milk feeds, three $(12 \%)$ had eczema at 3 months. Ten babies received soya feeds exclusively during the first 4 weeks, two $(20 \%)$ had eczema at 3 months. Of 35 babies who had received cows' milk exclusively, seven $(20 \%)$ had eczema at 3 months (Table 5).

The 475 infants in the study were selected because one or both parents had a history of eczema or asthma, or both. Of 376 with one parent affected by asthma or eczema (mild family history), $53(14 \%)$ developed eczema by 3 months. Sixty nine babies had one parent with both eczema and asthma and 30 had both parents affected with either eczema or asthma. As there was no significant difference in outcome between these two groups they were amalgamated and referred to as having a severe family history. Of the babies with this history, $27 \%$ developed eczema by 3 months, which was significantly more than those with a mild family history $\left(\chi^{2}=10.55, P<0 \cdot 01\right)$. Eight per cent of infants in the group that was not fed cows' milk had a severe family history compared with $3 \%$ in the group fed cows' milk.

Of the 470 infants for whom a definite statement was available on whether solids had been given during the first 3 months of life, only eight had had solids during the first 4 weeks. There was no significant difference in the proportion of infants with eczema at 3,6 , and 12 months between those who had solids during the first 3 months of life and those who had not.

A multivariate analysis was performed ${ }^{13}$ to examine the independent effects of type of milk (all breast milk $v$ any cows' milk), introduction of solids, social class, and family history of atopy on the cumulative prevalence of eczema at 3,6 , and 12 months. Family history and type of milk were significantly and independently associated with eczema at 3 months $\left(\chi^{2}=9.30,1 \quad \mathrm{df}, \mathrm{P}<0 \cdot 01\right.$ and $\left.\chi^{2}=8 \cdot 87,1 \mathrm{df}, \mathrm{P}<0 \cdot 01\right)$. For eczema at 6 and 12 
months only family history remained significantly associated $\left(\chi^{2}=6 \cdot 12,1 \mathrm{df}, P<0.02\right.$ and $\chi^{2}=4.43,1 \mathrm{df}$, $\mathrm{P}<0 \cdot 05)$. Social class and early introduction of solids appeared to have no independent effect $\left(\chi^{2}=0 \cdot 56,2\right.$ $\mathrm{df}, \mathrm{NS}$ and $\left.\chi^{2}=1 \cdot 69,1 \mathrm{df}, \mathrm{NS}\right)$.

\section{Discussion}

Despite careful intervention by the team $74 \%$ of mothers in the experimental group were unable or unwilling to breast feed exclusively for the three month period. Twenty six per cent of this group ( $35 \%$ of those who failed to breast feed exclusively) were persuaded, however, to use a soya preparation as an alternative instead of using cows' milk. Johnstone and Dutton suggested that dairy products were particularly sensitising in early infancy ${ }^{5}$ thus the use of soya was an attempt to avoid antigens. Matthew et al suggested that the protective functions of human milk might have a positive role in preventing allergy therefore the effect might be antigen non-specific. ${ }^{6}$ The similar outcome in this study for babies who were exclusively breast fed and those breast fed and given soya preparations provides at first sight support for Johnstone and Dutton's hypothesis. ${ }^{5}$ Other studies have not observed protection by soya feeds, ${ }^{12}$ and calves given soya feeds early in life have become allergic to soya. ${ }^{14}$

A detailed examination of the feeding diaries kept by mothers during this trial suggests that the lower prevalence of eczema in infants who were breast fed and soya fed than in infants who were breast fed and cows' milk fed may be due to their having less of the artificial feed. In the small numbers who were exclusively fed soya or cows' milk there was no difference in the prevalence of eczema at 3 months $(20 \%)$. Neither was there in those given only one or two soya or cows' milk feeds $(11 \%$ and $12 \%$, respectively,). There is therefore no evidence that soya is less likely to be associated with eczema at 3 months than cows' milk. If the infants who received soya preparations were excluded from the analysis and comparison made directly between the infants who were exclusively breast fed and those fed cows' milk the significant differences in the prevalence of eczema remain.

To interpret the data as an observational study the two groups should be comparable. Several variables that might have affected outcome were comparable in both groups but at least two were not: the babies who were fed cows' milk came from families who were more likely to be from social class III, IV, or V and to have mild parental histories of atopy. They were therefore less likely to develop eczema, ${ }^{3}{ }^{15}$ yet they developed more, though the difference was smaller than found in a previous study. ${ }^{6}$ The real difference in the prevalence of eczema therefore was probably greater than that observed. In addition, babies who had been exclusively breast fed for the first 4 weeks of life but who had received some cows' milk before 12 weeks tended to be those with a mild family history. This may explain why the effect was less sustained than before ${ }^{6}$ and associated more strongly with breast feeding in the first few weeks. With the increase in breast feeding and the belief that breast feeding protects against allergy more mothers with families at high genetic risk will probably choose to breast feed. Studies of this type will therefore become increasingly difficult and more liable to produce negative results that are artefacts.

Early studies assumed that the observed association of a high prevalence of eczema with cows' milk feed arose because this milk was especially allergenic, but others suggested the antigen non-specific hypotheses as cows' milk is only one of many foods causing eczema. Such a mechanism is possible as supplementary feeds given to suckling rats influence their IgE antibody response to an antigen that is not present in the feed. ${ }^{16}$ An example of an antigen nonspecific effect of infant feeding is that allergy to a particular pollen is less likely in infants who are weaned at the time of pollenation. ${ }^{17} \mathrm{~A}$ possible antigen non-specific mechanism for the protective effect of human milk might be an adjuvantising effect of the altered flora of the gut in those who receive artificial or supplemented feed. Interestingly, the flora of the gut of breast fed babies who were born recently differs from that reported some years ago. ${ }^{1819}$ This suggests that factors other than type of feed are implicated. Our data do not, however, discriminate between a transient effect of avoiding antigens or a more sustained effect on responsiveness, postulated previously, in which the sustained effect was on disease and the effect on $\operatorname{IgE}$ antibody responses was transient. ${ }^{6}$

The protective effect of breast feeding against the early development of infantile eczema seen here is far from a total one and reports suggest that there are many other possible neonatal environmental effects that may contribute to the outcome for the genetically susceptible: these require study. Even if the effect is antigen-specific, as cows' milk is one of the commonest foods causing allergic disease in later childhood, taking it for the first time later on in life when responses are more mature may result in a less prolonged and damaging response. If an antigen non-specific mechanism also operates its effect would be more likely to be sustained, as reported in experimental animals, ${ }^{16}$ therefore the protection might influence a wide range of immunopathological 
diseases, not only in atopics. Until there is evidence against this we suggest that all infants (not just those of atopic parents) should be exlusively breast fed for at least the first 3 months and partly breast fed for longer unless there is good reason against doing so, or evidence that these mechanisms do not apply in man.

Analyses of the laboratory data from this study will be published separately and the children will be followed up to see if there is any relation between patterns of early infant feeding and asthma.

We are indebted to Marian Cattermole and Wendy Jerman, health visitors; Margaret Anthony, midwifery sister; and Kate Illingworth for their work as members of the research team. We thank staff of the Bristol Maternity Hospital; the general practitioners, community midwives, and health visitors of Avon; Cow and Gate, who supplied the soya feed; and all families who cooperated in this study. The study was supported by the Medical Research Council.

\section{References}

1 Grulee CG, Sanford HN. The influence of breast and artificial feeding on infantile eczema. $J$ Pediatr 1936;9:223-5.

2 Butler NR, Golding J, Dowling S, Howlett B. From birth to five. London: Spastics International Medical Publishers, 1985;(in press).

${ }^{3}$ Kjellman, N. Atopic disease in seven year old children. Incidence in relation to family history. Acta Paediatr Scand 1977;66:465-71.

${ }^{4}$ Lubs MLE. Empiric risks for genetic counselling in families with allergy. J Pediatr 1972;80:26-31.

5 Johnstone DE, Dutton A. Dietary prophylaxis of allergic disease in children. $N$ Engl $J$ Med 1966;274:715-9.

6 Matthew DJ, Taylor B, Norman AP, Turner MW, Soothill JF. Prevention of eczema. Lancet 1977;i:321-4.

${ }^{7}$ Saarinen UM, Kajosaari M, Backman A, Siimes MA. Pro- longed breast feeding as a prophylaxis for atopic disease. Lancet 1979;ii:163-6.

${ }^{8}$ Guskay FL. Comparison of breast, cow and soy feedings in prevention of onset of allergic disease. Clin Pediatr (Phila) 1982;21:486-91.

${ }^{9}$ Hide DW, Guyer BM. Clinical manifestations of allergy related to breast and cows' milk feeding. Arch Dis Child 1981;56:172-5.

${ }^{10}$ Kramer MS, Moroz B. Do breast feeding and delayed introduction of solid foods protect against subsequent atopic eczema? $J$ Pediatr 1981;98:546-50.

"Fergusson DM, Horwood LJ, Beautrais AL, Shannon FT, Taylor B. Eczema and infant diet. Clin Allergy 1981;11:325-31.

12 Kjellman N, Johansson SGO. Soy versus cows' milk in infants with a biparental history of atopic disease: development of atopic disease and immunoglobulins from birth to 4 years of age. Clin Allergy 1979;9:347-58.

13 Baker RJ, Nelder JA. GLIM Manual: Release 3. Oxford: Oxford Numerical Algorithms Group, 1978.

14 Kilshaw BJ, Sissons JW. Gastrointestinal allergy to soyabean protein in preruminant calves. Antibody production and digestive disturbances in calves fed heated soyabean flour. Res Vet Sci 1982;27:361-5.

15 Taylor B, Wadsworth J, Golding J, Butler N. Breast feeding, eczema, asthma and hayfever. J Epidemiol Community Health 1983;37:95-9.

${ }^{16}$ Roberts SA, Soothill JF. Provocation of allergic response by supplementary feeds of cows' milk. Arch Dis Child 1982;57: 127-30.

${ }^{17}$ Saarinen UM, Kajosaari IM, Backman A. Birch pollen allergy in children. Role of milk feeding during the first birch season of life. Allergy 1982;37:345-50.

18 Simhon A, Douglas JR, Drasar BS, Soothill JF. Effect of feeding on infants' faecal flora. Arch Dis Child 1982;57:54-8.

19 Bullen CL, Tearle PV, Steward M. The effects of 'humanized' milks and supplemented breast feeding on the faecal flora of infants. J Med Microbiol 1977;10:404-13.

Correspondence to Dr R E Midwinter, Department of Epidemiology and Community Medicine, University of Bristol, Bristol BS8 2PR.

Received 4 March 1985 